\title{
Involvement of Gluconic Acid and Glucose Oxidase in the Pathogenicity of Penicillium expansum in Apples
}

\author{
Yoav Hadas, Israel Goldberg, Ophry Pines, and Dov Prusky
}

\begin{abstract}
First and fourth authors: Department of Postharvest Science of Fresh Produce, ARO, the Volcani Center, Bet Dagan, Israel 50250; first and third authors: Department of Molecular Biology; and second author: Department of Molecular Genetics and Biotechnology, The Hebrew University of Jerusalem, Faculty of Medicine, Israel 91120.

Accepted for publication 14 September 2006.
\end{abstract}

\begin{abstract}
Hadas, Y., Goldberg, I., Pines, O., and Prusky, D. 2007. Involvement of gluconic acid and glucose oxidase in the pathogenicity of Penicillium expansum in apples. Phytopathology 97: 384-390.

The contribution of gluconic acid secretion to the colonization of apple tissue by Penicillium expansum was analyzed by modulation (increase or decrease) of gluconic acid accumulation at the infection court. $P$. expansum isolates that express the most gox2 transcripts and concomitant glucose oxidase (GOX) activity and that secrete the most gluconic acid cause disease of apple at the fastest rate. Cul-

transcripts, produced less gluconic acid, and led to a $15 \%$ reduction in disease. Furthermore, the detection of significantly high levels of transcripts of gox 2 and GOX activity at the edge of the decaying tissue emphasize the involvement of GOX in tissue acidification of the decaying tissue. Taken together, these results emphasize the importance of GOX in the production of the gluconic acid that leads, in turn, to host tissue acidification. This acidification enhanced the expression of pectolytic enzymes and the establishment of conditions for necrotrophic development of $P$. expansum
\end{abstract} tures grown under reduced oxygen concentration generated fewer gox 2
There is a growing body of evidence indicating that filamentous fungi alter their environmental $\mathrm{pH}$ during pathogenicity as a means for modulation of fungal attack in several hosts $(14,19)$. Since $\mathrm{pH}$ is a critical factor in its attack strategy, the pathogen tailors ambient conditions to fit its offensive arsenal. For instance, certain fungi, such as Colletotrichum gloeosporioides (17) and Alternaria alternata (6), alkalinize their host tissues by producing significant amounts of ammonia. Other fungi, such as Sclerotinia sclerotiorum (14) and Botrytis cinerea (27), acidify their host tissues by producing oxalic acid, while Penicillium expansum, $P$. digitatum, and P. italicum secrete citric and gluconic acids (18).

Previous work of Prusky et al. (18) suggested that production of gluconic and citric acids by $P$. expansum acidifies the infection court, which acts in turn to activate fungal transcription of polygalacturonases leading to an increase in colonization. It was also suggested that acid conditions naturally found in more acid apples or artificially by exogenous treatment with organic acids, enhanced fungal colonization. The objectives in this work were to demonstrate whether the accumulation of organic acid plays a significant role in the pathogenicity of $P$. expansum on apple fruit.

Glucose oxidase (GOX) catalyses the oxidation of $\beta$-D-glucose to $\mathrm{H}_{2} \mathrm{O}_{2}$ and D-glucono-1,5-lactone, which hydrolyses spontaneously to gluconic acid (1). We demonstrate that gluconic acid produced by $P$. expansum strongly contributes to host acidification and enhanced fungal colonization of apple tissue. We have analyzed the relationship between gluconic acid accumulation and the colonization of apples infected by $P$. expansum by either (i) selection of natural isolates with increased GOX activity and gluconic acid accumulation; (ii) down

Corresponding author: D. Prusky; E-mail address: dovprusk@agri.gov.il Corresponding author: O. Pines; E-mail address: ophry@md.huji.ac.il

DOI: 10.1094/PHYTO-97-3-0384

C 2007 The American Phytopathological Society regulation of GOX resulting in inhibition of the secretion of gluconic acid; and (iii) localizing the capability to secrete gluconic acid and $\mathrm{H}_{2} \mathrm{O}_{2}$ at the leading edge of the hyphae. Our results support our hypothesis that gluconic acid accumulation by the colonizing pathogen is an important factor for enhanced pathogenicity of $P$. expansum in apple fruit.

\section{MATERIALS AND METHODS}

Apple fruits, fungal isolates, growth media, and fruit inoculation. Mature apple fruit cv. Golden Delicious were obtained from local suppliers on the day of the experiment. Single spores of each of three different isolates of $P$. expansum were obtained from decayed apple fruit. Isolates Pe-21 and Pe-16 were obtained from decayed local cvs. Grand Alexander and Golden Delicious apples, respectively, and isolate Pe-23 was obtained from a decayed Golden Delicious apple at Beltsville Agricultural Research Center (BARC), Agricultural Research Service-United States Department of Agriculture (ARS-USDA), Beltsville, MD (29). If not specified otherwise, Pe-21 was used in the various experiments. One-week-old conidia, harvested from potato dextrose agar (PDA) plates (Difco, Detroit, MI) were used for mycelial growth and fruit inoculation assays. The fruit were inoculated by placing $10 \mu \mathrm{l}$ of a conidial suspension containing 2 $\times 10^{6}$ spores $/ \mathrm{ml}$ on each of four 2-mm-deep, 2-mm-diameter wounds spaced around a circle on the upper part of the stem side of the fruit. Following inoculation, the fruit were incubated at $25^{\circ} \mathrm{C}$ in covered plastic containers containing wet paper towels, until decay symptoms developed. In some experiments, the wound sites were treated every $24 \mathrm{~h}$ with $50 \mu \mathrm{l}$ of $0.25 \mathrm{M}$ citric or gluconic acid. Double-distilled water was used as a control. To analyze the effects of $\mathrm{O}_{2}$ concentrations on decay development and gluconic acid production, infected fruit were incubated for 24 $\mathrm{h}$ at 22 to $23^{\circ} \mathrm{C}$ and $90 \%$ relative humidity and then transferred to 
30 -liter containers for $96 \mathrm{~h}$ at $25^{\circ} \mathrm{C}$. The containers were aerated with different $\mathrm{O}_{2}$ concentrations at a constant flow rate of 200 $\mathrm{ml} / \mathrm{min}$. Each experiment involved at least 10 apples, and the decayed area was averaged over 10 fruits. The experiment was repeated three times and the results of a single representative experiment are presented.

GOX activity, transcript expression, and gluconic acid accumulation. GOX production, gluconic acid accumulation, and gox expression by $P$. expansum were analyzed in liquid medium after placing $500 \mu \mathrm{l}$ of $2 \times 10^{6}$ spores $/ \mathrm{ml}$ suspension of the pathogen into $25 \mathrm{ml}$ of yeast sucrose medium (YSM) in 125-ml flasks. The YSM contained $15 \mathrm{~g}$ of sucrose, $2 \mathrm{~g}$ of yeast extract (Difco), $1 \mathrm{~g}$ of $\mathrm{K}_{2} \mathrm{HPO}_{4}$, and $0.5 \mathrm{~g}$ of $\mathrm{MgSO}_{4} \cdot 7 \mathrm{H}_{2} \mathrm{O}$ per liter. medium, at $\mathrm{pH} 5.5$. The cultures were shaken with an orbital shaker (Orbit Environ-Shaker, Lab Line, Barnstead Intl., Dubuque, IA) at $150 \mathrm{rpm}$ and incubated at $25^{\circ} \mathrm{C}$ for $48 \mathrm{~h}$. Cultures were harvested by vacuum filtration through a sterile Büchner funnel fitted with a filter paper and the remaining mycelia were washed twice over a filter paper with $50 \mathrm{ml}$ of sterile distilled water. The washed mycelia were resuspended in $25 \mathrm{ml}$ of GOX induction medium containing $60 \mathrm{~g}$ of sucrose, $7 \mathrm{~g}$ of $\mathrm{NaNO}_{3}, 3 \mathrm{~g}$ of peptone (Difco), $1 \mathrm{~g}$ of $\mathrm{KH}_{2} \mathrm{PO}_{4}, 0.5 \mathrm{~g}$ of $\mathrm{MgSO}_{4} \cdot 7 \mathrm{H}_{2} \mathrm{O}$, and $0.5 \mathrm{~g}$ of $\mathrm{KCl}$ per liter medium. The initial $\mathrm{pH}$ value for each flask was determined after the medium had been autoclaved but prior to inoculation, and adjusted to 6.5 with $\mathrm{NaOH}$.

To analyze the effects of $\mathrm{O}_{2}$ concentration on the in vitro production of GOX and gluconic acid, three flasks containing secondary medium were inoculated for each treatment. The cultures were exposed to a constant flow $(50 \mathrm{ml} / \mathrm{min})$ of gas with different $\mathrm{O}_{2}$ concentrations that penetrated and exited the flask through a rubber stopper in the flask. The cultures were harvested by vacuum filtration as described above after $48 \mathrm{~h}$, and the filtrates were used for determination of $\mathrm{pH}$, quantification of gluconic acid, and determination of GOX activity. The mycelium was frozen in liquid nitrogen and then lyophilized for RNA extraction and dry weight determination. The experiments were repeated four times, and the results of a single representative experiment are presented since there were no significant differences among the experimental repeats. The average values of each treatment (three flasks per treatment) did not differ by more than 2 to $3 \%$ between experiments.

To analyze gox expression by $P$. expansum in apples, washed mycelia obtained after $48 \mathrm{~h}$ of growth in YSM were collected and packed into wounds in the apple tissue that were $6 \mathrm{~mm}$ in diameter and $4 \mathrm{~mm}$ deep, and were produced by a cork borer. Decay symptoms started to spread around each wound $24 \mathrm{~h}$ after inoculation and incubation of the apples at $25^{\circ} \mathrm{C}$, and the packed mycelia were removed from the wound 24 or $48 \mathrm{~h}$ after the transfer for RNA extraction.

Atmospheric $\mathrm{O}_{2}$ regulation and determination. The concentration of $\mathrm{O}_{2}$ in the containers or flasks was adjusted by mixing air $\left(21 \% \mathrm{O}_{2}, 0.03 \% \mathrm{CO}_{2}\right.$, and $\left.78.97 \% \mathrm{~N}_{2}\right)$ with increasing amounts of $100 \% \mathrm{~N}_{2}$ to result in the appropriate proportions, and maintained constant in a humidified gas stream flowing at 100 $\mathrm{ml} / \mathrm{min}$. The stream was monitored during and at the end of the experiments. Samples of $4 \mathrm{ml}$ of gas from each treatment were injected into a Model 29 gas chromatograph (Fisher-Hamilton, Two Rivers, WI) equipped with a thermal conductivity detector and a CTR 1, $182 \mathrm{~cm} \times 0.61 \mathrm{~cm}-\mathrm{OD}$ SS column (Alltech, Deerfield, IL) and operated at 22 to $23^{\circ} \mathrm{C}$ with helium flowing at $30 \mathrm{ml} / \mathrm{min}$ as the carrier gas. The data were collected with a 3396 integrator (Hewlett-Packard Co., Avondale, PA).

Analysis of organic acids. For the extraction of organic acids, 0.2-g samples of apple pulp were ground in a Mini Beadbeater (Biospec, Bartlesville, OK) operated at 2,500 rpm in the presence of $0.8 \mathrm{ml}$ of $\mathrm{H}_{2} \mathrm{O}$ and $0.5 \mathrm{~g}$ of 0.5 -mm-diameter glass beads. The ground tissues were then centrifuged for $10 \mathrm{~min}$ at $20,800 \times \mathrm{g}$.
The supernatant fractions obtained were filtered through $0.2-\mu \mathrm{m}$ cellulose acetate filters (Schleicher \& Schuell, Dassel, Germany) and kept at $-20^{\circ} \mathrm{C}$ until analysis.

Citric acid in culture filtrates and apple extracts was analyzed with a high pressure liquid chromatograph apparatus equipped with an L-6200 Intelligent pump (Hitachi Scientific Instrument Co. Ltd., Tokyo). Samples of $20-\mu$ filtrates were injected into a $250 \times 4 \mathrm{~mm} 100-\mathrm{C} 18$ column (Eurospher, Berlin) with a mobile

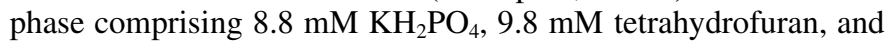
$7.6 \mathrm{mM}$ acetonitrile, adjusted to $\mathrm{pH} 2.2$ with phosphoric acid. The flow rate was $0.7 \mathrm{ml} / \mathrm{min}$. The citric acid was detected at $210 \mathrm{~nm}$ with an L-4200 detector (Hitachi), and quantified by comparison with an external standard of citric acid (Sigma-Aldrich Israel Ltd., Rehovot, Israel), with an integrator model 3396 (Hewlett-Packard Co.).

The amount of gluconic acid produced in culture filtrates and apple extracts was measured with a commercial enzyme kit for the determination of D-gluconic acid/D-glucono- $\delta$-lactone (RBiopharm, Darmstadt, Germany).

Measurement of pH. The $\mathrm{pH}$ was measured with a single-pore flat or a double-pore slim electrode (Hamilton, Bonaduz, Switzerland) connected to a ThermoOrion Model 720A Plus pH meter (Orion, Beverly, MA). The $\mathrm{pH}$ of the medium was measured in 3-ml aliquots sampled after fungal inoculation, and three replicates were tested for each treatment. The $\mathrm{pH}$ of the mesocarp was measured by placing the $\mathrm{pH}$ electrode directly against the exposed tissue at several points along a transverse cut through the infection site, made with a scalpel blade. All measurements were repeated on 10 to 12 fruit, for a total of at least 30 measurements.

Assay of GOX activity. GOX activity was measured in culture filtrates of secondary media and in extracts of apple tissues. The extracts were prepared by first homogenizing $10 \mathrm{~g}$ of tissue followed by centrifugation at $14,470 \times g$ for $20 \mathrm{~min}$. The supernatant fractions were separated and kept at $-20^{\circ} \mathrm{C}$ until use. The samples were concentrated by filtration through an Amicon Ultra 30,000 MWCO centrifugal filter device (Millipore Corporation, Bedford, MD), and the GOX activity was measured. The control for GOX production in vitro was the inoculated secondary media, used immediately after the addition of the hyphae. Extracts of wounded-healthy tissue of the opposite side of the inoculated fruits were used as a negative control for the inoculated apple tissue. The reaction mixtures contained $20 \mu \mathrm{g}$ of horseradish peroxidase type 1 (Sigma-Aldrich), $1.8 \%$ D-glucose, $0.1 \%$ o-dianisidine (Sigma-Aldrich), and $100 \mu \mathrm{l}$ of the sample in $1.5 \mathrm{ml}$ of $0.1 \mathrm{M}$ potassium phosphate buffer at $\mathrm{pH}$ 6.5. The oxidation of o-dianisidine by a peroxidase-coupled reaction was measured by the increase in the absorbance at $460 \mathrm{~nm}$. Measurements of the GOX activities were repeated at least three times. One unit of activity was defined as the amount of enzyme that caused the increase in absorbance at $460 \mathrm{~nm}$ by one unit per minute at $25^{\circ} \mathrm{C}$ and at $\mathrm{pH}$ 6.5. Protein concentrations in samples were measured with the Protein-Assay instrument (BioRad Laboratories, Munich), with bovine serum albumin (SigmaAldrich) used as the standard. The results of representative measurements are presented.

Cloning of a fragment of gox gene from $P$. expansum. Genomic DNA was isolated from the mycelium of $P$. expansum with a DNeasy kit (QIAGEN, Santa Clarita, CA). cDNA was prepared from $P$. expansum mycelia grown in the secondary inducing medium and collected by vacuum filtration. Mycelia collected $10 \mathrm{~h}$ after growth were quickly frozen in liquid nitrogen and then lyophilized. The total RNA fractions were prepared with the RNeasy Plant Mini Kit (QIAGEN). Contaminating DNA was removed by digestion with DNAse (Turbo DNA Free Set, Ambion Inc., Austin, TX). Reverse transcription reactions were carried out with the Reverse-it 1st strand synthesis kit (ABgene, Surrey, UK). The RNA concentration used in the reaction was $80 \mathrm{ng} / \mu \mathrm{l}$. 
To design degenerate primers, the amino acid sequences encoding for three gox genes-P. amagasakiense (GenBank accession no. AF012277) (10), Aspergillus niger (GenBank accession no. AJ294936) (9), and Talaromyces flavus (GenBank accession no. U56240) (16)—were compared by multiple alignment, and primers were designed according to the sequences of the homologous areas of the genes. The primers used were the forward GTYATYGAAARSGGYTTCTAYGAGTC and the reverse CWATGCCAGARTRTTCSARGATC. Fragments from the gox genes were amplified by PCR of genomic DNA or cDNA with the designed primers. In each case an amplification product of the expected size was cloned into plasmid pGEM-T easy (Promega, Madison, WI), sequenced and compared to ggox (GenBank accession no. AJ294936) (9) and go (GenBank accession no. J05242) (8) from A. niger.

Real-time PCR analysis. Mycelia of Pe-21 and Pe-16 were obtained from secondary cultures by vacuum filtration after various periods of incubation in the induction medium. RNA was extracted and cDNA was synthesized as described above. Expression levels of gox 1 and gox 2 were assayed by real-time PCR analysis and were normalized to the expression level of $28 \mathrm{~S}$ rRNA. PCR amplification of gox genes was carried out in $15-\mu l$ aliquots of reaction mixtures containing $7.5 \mu \mathrm{l}$ of cDNA template (when the expression of gox 1 or gox 2 was measured the sample was diluted 1:10, and dilutions of 1:1, 1:10, 1:100, and 1:1,000 were used for standard curves; when the expression of 28s rRNA was measured the sample was diluted to $10^{-4}$ and dilutions of $10^{-3}$, $10^{-4}, 10^{-5}$, and $10^{-6}$ were used for standard curves), $1.875 \mu \mathrm{l}$ of each primer as described below, and $3.75 \mu 1$ of Absolute QPCR Green ROX Mix (ABgene, Rochester, NY). The PCR assays were run on a Rotor-Gene 3000 Real-Time Cycler (Corbett-Research,
Mortlake, Australia) with the following cycling conditions: $95^{\circ} \mathrm{C}$ for $15 \mathrm{~min}$, followed by 40 cycles of $95^{\circ} \mathrm{C}$ for $3 \mathrm{~s}, 60^{\circ} \mathrm{C}$ for $15 \mathrm{~s}$, and $72^{\circ} \mathrm{C}$ for $10 \mathrm{~s}$. The Syber Green signal was measured at the end of every cycle, and a final melting step from 72 to $95^{\circ} \mathrm{C}$ for 2 min was used for generating a melting curve. The primers for each gene were designed with the Primer Express version 2 software (Applied Biosystems, Foster City, CA). To optimize the concentrations of the primers, several reactions with different concentrations of each of the primers were performed. Primer efficacy was examined by running template solutions of various concentrations and verifying a slope of $-3.2 \pm 0.2$ in a curve of cycle threshold $(\mathrm{Ct})$ versus log (template concentration). For the optimization of gox2 and 28s rRNA primers, a mixture of cDNAs of the two isolates Pe-21 and Pe-16 was used as a template. For the optimization of gox primers a pGEM-T plasmid carrying a fragment of the gene was used as a template. The primer sequences, final concentrations, and product size were as follows: for gox 1 gene 5'CGGAACAACGGAGAACCCTA $400 \mathrm{nM}$ and 5'GGGACCCCACAGTGGAAATC $400 \mathrm{nM}, 100 \mathrm{bp}$; for gox2 gene 5'ACAACCGCACCGAGATTGTT $100 \mathrm{nM}$ and 5'AGGTTGACCCTCCCAGTCCTT $175 \mathrm{nM}$, $50 \mathrm{bp}$; and for 28s rRNA gene 5'GGAACGGGACGTCATAGAGG $175 \mathrm{nM}$ and 5'AGAGCTGCATTCCCAAACAACT 175 nM, 100 bp.

The standard curves and gene concentrations were calculated with the Rotor-Gene software, version 6 (Corbett-Research) using the absolute quantitation analysis. The amount of the GOX cDNA relative to that of 28 s (constitutively expressed) is referred to as "gox relative expression"; the reported values of gox relative expression are averages of two replicates. Each experiment was repeated three times, and the results of a single representative experiment are presented.

\section{A. nigex ggox \\ A. niger go \\ P. expansum gox 1 \\ P. expansum gox2}

A. niger ggox

A. niger go

P. expansum gox 1

P. expansum gox2

A. nigex ggox
A. nigex go
P. expansum gox 1
P. expansum gox 2

A. niger ggox

A. niger go

P. expansum gox 1

P. expansum gox2

A. nigex ggox
A. nigex go
P. expansum gox1
P. expansum gox 2

A. niger ggox

A. niger go

P. expansum gox1

P. expansum gox2

1
1
1

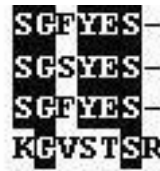

DRFPL

LVEDLVIA IIEDLII

YGEIF YGD IF

GSET

DHAY 0 TUELATMTL TELIRSGKG SWDAYETUELAT TMU QTALIRSGKG KGVSTSR T SVLSLKHLYHYGDIF GT SWOMFE TIPLAIHURTEIVRSGKG
50

50

50

51
99

99

99

100
100 MRKDVAAGHFDPSCHGTKGTVHVGPRDTFDDFTPIIDALUIT TEMIGVP 149

100 WAKOIAAGHYFHASCHGVUGTUHAGPRD TGDDYSP IVKALUSAVEDRGUP 149

100 SDVEIAAGHFYNSCHGTUGTVHAGPRMAGEP ISP IIKTL IDSAKERG VP 149

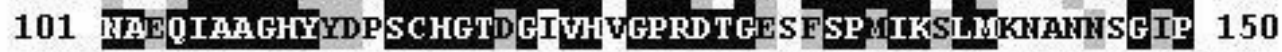

150 TKKDL GC GDPHGUSTFPUTLHED QURSDARREHLLPKYQRPKLQVLTGQ 199

150 TKKDF GC EDPHGVSUFPUTLHED QVRSDARREHLLPKYQRPKL QULTG QY 199

150 TQLDFHC GVPRGISUIPHALHED QVRSDARREHLLPKYKRPKLQVLTGQF 199

151 VQKDLGCGVPHGISMILIZD VHED QTRSDARREHLLPKYQRSILKILTGQM 200

200 VGKULLD 0---HNTVP--KAVGUEFGTKANTFWVAKHEVLLARASAVS 244

200 VGKULLS 0---HGTTP--RAVGUEFGTHEGHT HUVIAKHE ULLAAGSAVS 244

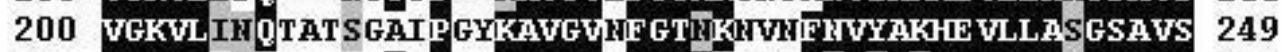

201 UGKULFD T---TTTTP--KAVGUHFGTHAKVHFDUHIRRE ULLASGSAVS 245

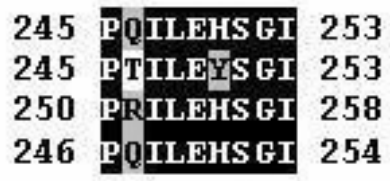

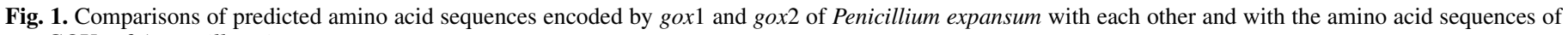
two GOXs of Aspergillus niger. 
Macroscopic and microscopic detection of $\mathrm{H}_{2} \mathrm{O}_{2}$ in fruit tissue. $\mathrm{H}_{2} \mathrm{O}_{2}$ was detected macroscopically by diaminobenzidine (DAB) (Sigma fast DAB tablets) staining. DAB polymerizes instantly, and develops a localized dark color as soon as it comes into contact with $\mathrm{H}_{2} \mathrm{O}_{2}$ in the presence of peroxidase (26). A dark color was observed in 1-mm slices of $P$. expansum-infected Golden Delicious apples after dipping the tissues in $0.07 \%$ solution of DAB. Similar infected tissues were immersed in distilled water as control. Sliced tissues were photographed immediately before and $20 \mathrm{~h}$ after staining.

For microscopic detection of oxidative changes produced by mycelia of $P$. expansum, 2-mm slices of infected Golden Delicious apples were immersed in $50 \mathrm{mM} 2$-[ $N$-morpholino]ethanesulfonic acid assay buffer, $\mathrm{pH} 6.2$, containing $10 \mu \mathrm{M}$ dichlorodihydrofluorescein diacetate $\left(\mathrm{H}_{2}\right.$ DCFDA) (Molecular Probes, Eugene, OR) for $30 \mathrm{~min}$ at room temperature. Slices were then washed with the same buffer. Oxidation of the $\mathrm{H}_{2}$ DCFDA by $\mathrm{H}_{2} \mathrm{O}_{2}$ was detected as the highly green fluorescent $2^{\prime}, 7^{\prime}$ dichlorofluorescein that was monitored by fluorescence spectroscopy using excitation and emission wavelengths of 502 and $523 \mathrm{~nm}$, respectively. Images were acquired using an Olympus IX81 confocal laser-scanning microscope system (Olympus, Tokyo). Confocal images were obtained via UPlanApo $10 X 0.40$ objective lens at an excitation wavelength of $488 \mathrm{~nm}$ (Argon laser), BA515-525 emission filter for $\mathrm{H}_{2}$ DCFDA, and BA660 IF emission filter for autofluorescence. Transmitted-light images were acquired using Nomarski differential interference contrast.

\section{RESULTS}

gox regulation of gluconic acid production in $P$. expansum. To determine the relative expression of the two genes encoding putative proteins with GOX activity, we first cloned DNA fragments of gox genes from the fungus based on published gox sequences $(9,10,16)$. Fragments from two different gox genes of $P$. expansum were generated and cloned by standard PCR technology. One fragment, designated gox1, was 784 bp (accession no. AY669127) and was isolated from an amplicon generated from genomic DNA. The second fragment, designated gox2, was 761 bp (accession no. DQ157372) and was isolated from an amplicon generated from cDNA produced from RNA after growth on GOX inductive medium. The two putative GOX genes shared $64 \%$ identity and $85 \%$ similarity (Fig. 1). A pairwise comparison to the A. niger gox genes ggox and go indicated that gox 2 shared a similar degree of identity (i.e, 64 and 69\% identity and 82 and $84 \%$ similarity, respectively). Between the two GOX fragments of $A$. niger there was an identity of $87 \%$ and a similarity of $94 \%$.

The relationship between increased gox expression, gluconic acid accumulation, and pathogenicity of $P$. expansum. To examine the relationship between increasing secretion of organic acids and pathogenicity we selected natural isolates of $P$. expansum that exhibited increasing levels of aggressiveness. The rates of decay development caused by three isolates, when inoculated into apple wounds, increased in the order Pe-21 $<$ Pe-23 < Pe-16: 5 days after infection, the decayed areas associated with the three isolates were 200,235 , and $290 \mathrm{~mm}^{2}$, respectively (Fig. 2A). The increase in the decayed area was proportional to the increase in gluconic acid accumulation (Fig. 2B) and to the decrease in tissue pH (Fig. 2C). The most aggressive isolate (isolate $\mathrm{Pe}-16$ ) secreted the largest amount of gluconic acid $(8,000 \mu \mathrm{g} / \mathrm{g}$ fruit weight [fw] ) and caused a decrease of 0.85 units in the $\mathrm{pH}$ of the plant tissue. The least aggressive isolates, Pe-23 and Pe-21, secreted 6,400 and 3,100 $\mu \mathrm{g} / \mathrm{g}$ fw gluconic acids, respectively, and reduced the $\mathrm{pH}$ by 0.7 and 0.5 units, respectively. All three isolates caused a significant increase in the concentration of citric acid relative to the control but the amount of acid that accumulated was similar in all three isolates (Fig. 2B). When gluconic acid or citric acid (at $0.25 \mathrm{M}$ ) was added independently to an infected wound, fungal colonization increased by 43 and $23 \%$, respectively (data not shown).

To assess whether gox transcript levels and activity of GOX were correlated with the accumulation of gluconic acid with fungal colonization (Fig. 2), we compared these parameters during colonization and fungal growth in vitro in the highly and less aggressive Pe-16 and Pe-21 strains, respecttively. The expression of gox 1 and gox 2 under GOX-inducing conditions in both isolates indicated that transcripts of gox 2 were expressed both in vivo and in vitro, whereas gox 1 was expressed only in vitro at a level approximately 80 times lower than the expression of gox2 (data not shown). Overall GOX activity in Pe16 was more than threefold greater than in Pe-21 $12 \mathrm{~h}$ after transfer to inducing media (1.70 compared with 0.55 units/g protein). The relative expression of gox 2 at 9 and $12 \mathrm{~h}$ after transfer was 250- and 14-fold greater in Pe-16 compared to Pe-21 (Fig. 3).

Effect of reduced levels of oxygen concentration on reduced expression of gox2, gluconic acid accumulation, and pathogenicity of $\boldsymbol{P}$. expansum. The reduction of percent oxygen in culture from 21 to $15 \%$ or to $10 \%$ resulted in a 15 and 250- fold decrease in gox2 expression, a 2.6- and 19-fold reduction in GOX activity, and a 1.5- and 5.5-fold reduction in gluconic acid concentration (Fig. 4). Overall growth at either 15 or $10 \%$ oxygen did not appear affected, as fungal dry weights were similar to those found at $21 \%$ oxy-gen. Reduction in percent oxygen to 5 or $3 \%$ led to even fewer gox 2 transcripts, less GOX activity and gluconic acid accumulation, and also led to a significant reduction in fungal growth (Fig. 4).

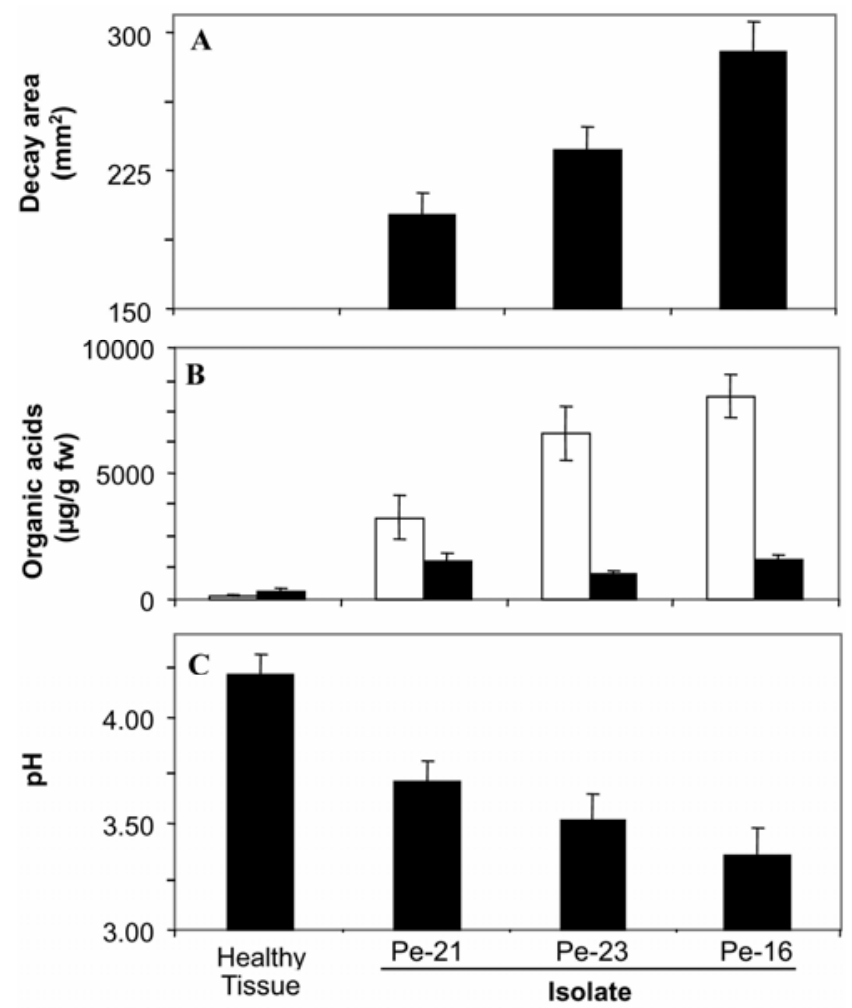

Fig. 2. Effect of Penicillium expansum isolates on the $\mathrm{pH}$ and on the production of organic acids in infected cv. Golden Delicious apples. A, Decayed area 5 days after inoculation with $P$. expansum; B, Amounts of organic acids (dark column indicates citric acid and bright column indicates gluconic acid); and $\mathbf{C}, \mathrm{pH}$ of the infected tissue. Average values of 10 replicates $( \pm \mathrm{SD})$ are presented. 


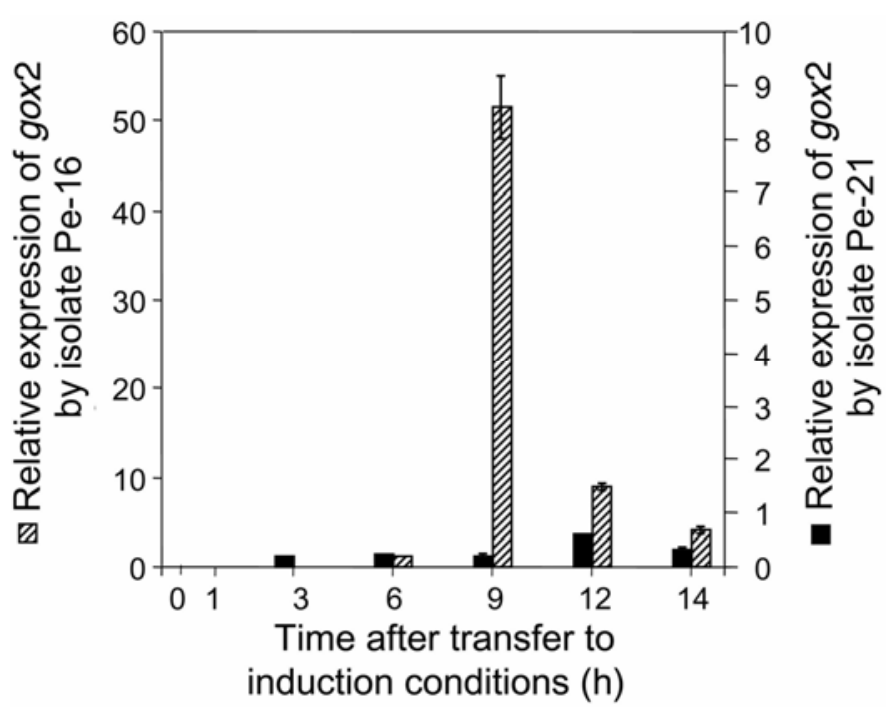

Fig. 3. Differential expression of gox 2 of Penicillium expansum isolates with different levels of aggression. RNA from mycelia of highly aggressive (Pe-16) and less aggressive (Pe-21) P. expansum strains were extracted at different lapsed times after transferring into the secondary inducible medium. gox 2 expression was detected by real-time PCR analysis. The gox 2 relative expression values are the averages $\pm \mathrm{SD}$ of two replicates. The experiment was repeated three times and the results of a single representative experiment are shown.
Exposure of $P$. expansum-infected apples to an oxygen concentration of $10 \%$ reduced gluconic acid accumulation at the leading edge of colonized tissue from 2,710 to $962 \mathrm{mg} / \mathrm{liter}$, and reduced tissue colonization by $15 \%$, i.e., from 410 to 350 $\mathrm{mm}^{2}$. A further decrease in oxygen concentration to $3 \%$ reduced gluconic acid accumulation and host colonization by 84 and $26 \%$, respectively, as compared to their levels at $21 \% \mathrm{O}_{2}$ (Fig. $5)$.

Localization of GOX activity, $\mathrm{H}_{2} \mathrm{O}$. production and gluconic acid secretion during decay development by $P$. expansum. GOX activity could not be detected in the extracts of healthy tissue. GOX-specific activities of 0.11 and 0.04 units/g protein were measured, respectively, at the leading edge and in the middle of the area decayed by $P$. expansum. The $\mathrm{pH}$ of healthy tissue was approximately 4.2 , in contrast to that of leading edge (3.7) or that in the middle of the colonized area (3.5).

$\mathrm{H}_{2} \mathrm{O}_{2}$, a byproduct of GOX activity and other oxidative changes, was detected in decayed apple tissues by the brown color following staining with DAB (Fig 6B) in comparison with the light brown color of the water control (Fig. 6A). Oxidative change produced by mycelia was also detected mostly inside (but also outside) the fungal hyphae by the fluorescence of dichlorodihydrofluorescein diacetate at the leading edge of the decaying area (Fig. 6C), suggesting that $\mathrm{H}_{2} \mathrm{O}_{2}$ is released to the decaying surrounding area.
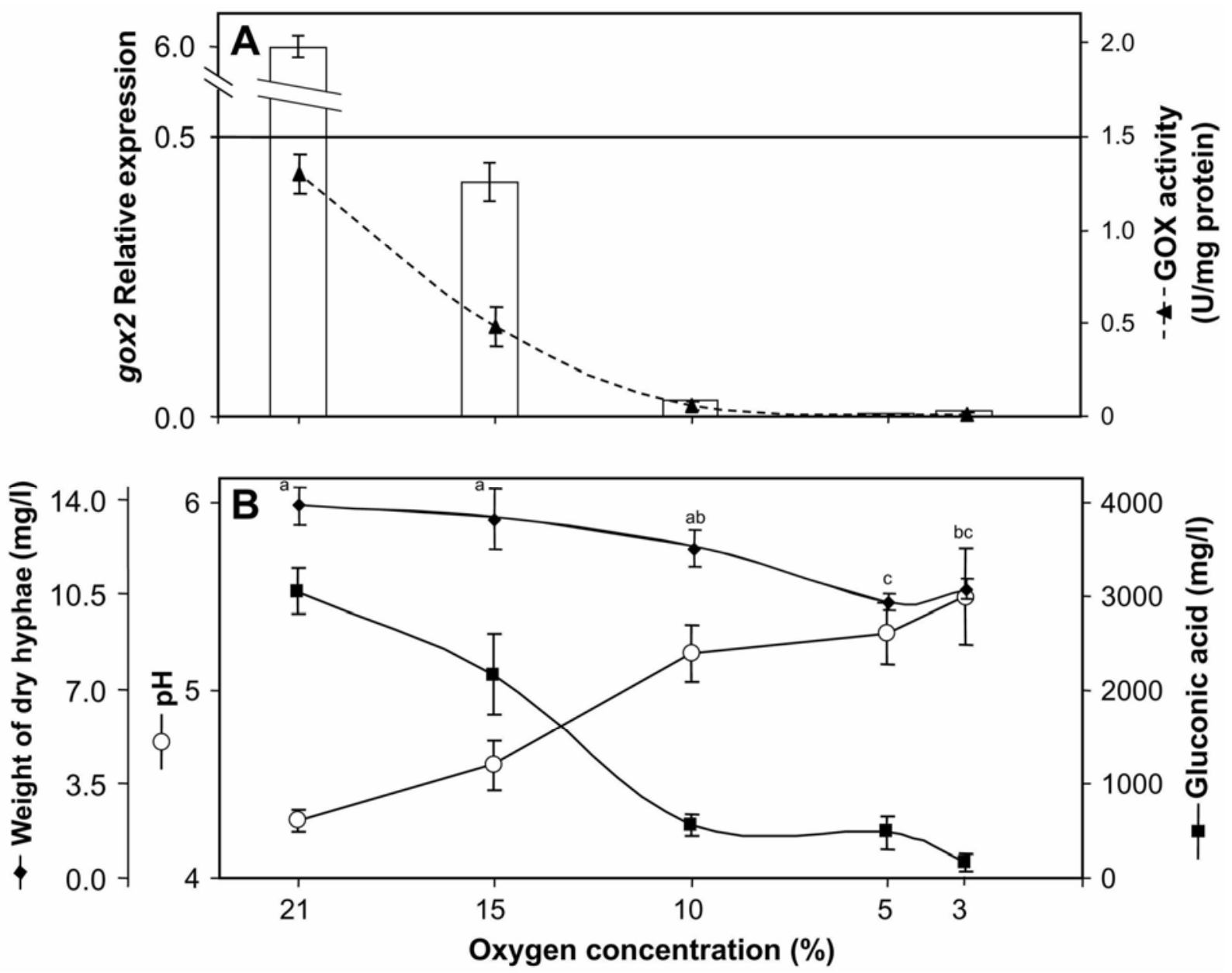

Fig. 4. Effects of atmospheric $\mathrm{O}_{2}$ concentration on the transcript level of gox2, GOX activity, and gluconic acid accumulation by Penicillium expansum. A, Relative expression of gox 2 and GOX activity in culture media $10 \mathrm{~h}$ after P. expansum hyphae were transferred to inductive conditions and exposed to mixtures of gases containing reduced $\mathrm{O}_{2}$ levels; and $\mathbf{B}$, Concentration of gluconic acid, medium $\mathrm{pH}$, and weight of dry hyphae. Average values $\pm \mathrm{SD}$ of three replicates of the relative expression of gox2, GOX activity, concentration of gluconic acid, $\mathrm{pH}$, and fungal dry weight are presented. Dry weight of the fungal hyphae as affected by reducing atmospheric oxygen levels was also analyzed statistically by Student's $t$ test; different letters indicate significant differences at $P \leq 0.05$. 


\section{DISCUSSION}

Gluconic and citric acids are the main organic acids produced by $P$. expansum, $P$. digitatum, and $P$. italicum during these fungi's necrotrophic colonization in fruits (18). It was suggested that changes in external $\mathrm{pH}$ during fruit infection due to these acids in turn favors the production of fungal pectolytic enzymes (18). The addition of exogenous gluconic acid or citric acid at the $P$. expansum infection site significantly enhanced decay development, supporting the hypothesis that these acids contributed to disease development (18). However, the data of the present work suggest that gluconic acid is the main organic acid contributing to the colonization of $P$. expansum: (i) aggressive isolates of $P$. expansum secreted significantly higher amounts of gluconic acid, whereas the amounts of citric acid accumulated were much lower and did not change correlatively with the increase in the aggressiveness of the isolates; (ii) addition of 0.25 $\mathrm{mM}$ gluconic acid to the infected fruit tissue increased Penicillium colonization twofold compared with similar concentrations of citric acid and (iii) GOX activity was detected at the leading edge of the decaying tissue, thereby localizing the production site of gluconic acid to the decay development front. Thus, we suggest that gluconic acid is the main acid contributing to $P$. expansum host acidification and that this strengthens the association between gluconic acid accumulation and virulence of $P$. expansum. Gluconic acid may further facilitate fungal colonization by chelating $\mathrm{Ca}^{2+}$ ions, weakening the host cell wall $(14,15)$, or by directly affecting cell death $(5,25)$.

GOX activity could not be detected in healthy apple tissues but was readily measured in the middle of the decayed area in apples infected by $P$. expansum. At the leading edge of the decayed tissue, GOX activity was nearly three times higher than in the middle of the decayed area. Genes encoding GOX have been cloned from several strains of Aspergillus and Penicillium sp. as well as from $T$. flavus and $B$. cinerea $(8,9,10,12,16,20)$. Two putative genes (gox 1 and gox 2 ) encoding GOX were detected in $P$. expansum and shared significant nucleotide and pre-dicted amino acid similarity with GOX genes from A. niger $(8,9)$. In the present study the expression of gox 1 could not be de-tected in vivo, whereas gox 2 was highly expressed both in vivo and in vitro. It is possible that the two gox genes of $P$. expansum are expressed under different conditions: gox 2 is expressed during the pathogenic process, whereas gox 1 is expressed under conditions not encountered in the present study.

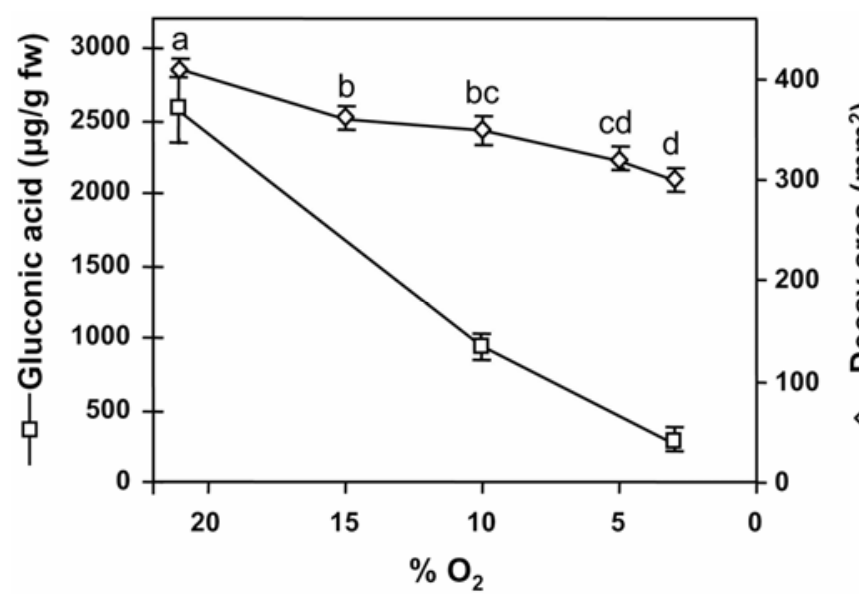

Fig. 5. Effects of atmospheric $\mathrm{O}_{2}$ concentration on gluconic acid accumulation (expressed as micrograms per gram of fresh weight [fw] of fruit) and virulence (expressed as decay area) in apples inoculated with Penicillium expansum at $25^{\circ} \mathrm{C}$. Average values $\pm \mathrm{SD}$ of seven replicates of gluconic acid concentration and decayed area are presented. Effect on the decayed area of reducing atmospheric oxygen levels was analyzed statistically by Student's $t$ test; different letters indicate significant differences at $P \leq 0.05$.
The production rate of GOX and the synthesis of gluconic acid has been shown to be affected by various conditions such as glucose levels, $\mathrm{pH}$ values $(1,22)$, and oxygen levels $(7,23,28)$. Glucose accounts for almost $50 \%$ of the concentration of the total soluble solids (TSS) in fruits, a factor that describes fruit sweetness. Apple TSS generally increases from between 7 and $8 \%$ to between 13 and $14 \%$ during fruit growth and postharvest ripening, conditions under which $P$. expansum commonly attacks (13). Semashko et al. (24) showed that GOX activity by $P$. funiculosum showed higher catalytic activity at $\mathrm{pH}$ above 6.0 than at lower $\mathrm{pH}$ values. This is in contrast to our work where we found that the $\mathrm{pH}$ of most of the infected fruits was below 6.0 (18).

One other factor modulating the rate of GOX activity and the synthesis of gluconic acid that was tested was the $\mathrm{O}_{2}$ concentration $(7,23,28)$. Oxygen-sensing and oxygen-responsive genes have been studied in yeasts $(2,11)$, but there have been only a few reports on the effect of $\mathrm{O}_{2}$ concentration on the expression of virulence genes in filamentous fungi. The reduction in the accumulation of gluconic acid under anoxia supports the
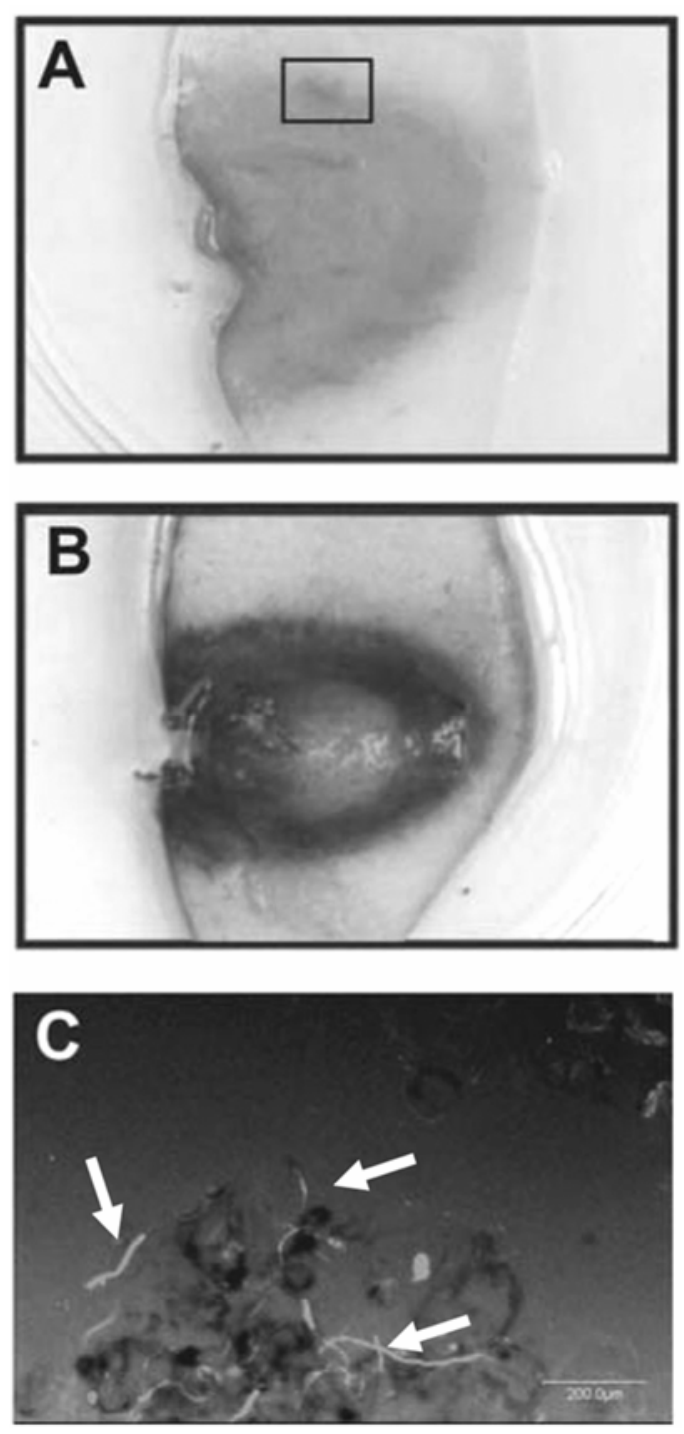

Fig. 6. Detection of oxidative changes in Golden Delicious apples inoculated with Penicillium expansum. Slices of inoculated apples were A, immersed in water; B, stained with diaminobenzamine (DAB) solution for $20 \mathrm{~h}$; or $\mathbf{C}$, immersed in dichlorodihydrofluorescein diacetate for microscopic detection of oxidative changes at the decay edge (marked by the square in A). Oxidative changes were detected mostly inside the hyphae (see arrows) and arround the fungal hyphae. No fluorescence was observed in the healthy tissue (upper part of C). Images were acquired using a confocal laser-scanning microscope. 
hypothesis that the reduction of atmospheric $\mathrm{O}_{2}$ inhibits GOX activity and the biosynthesis of this organic acid by P. expansum. Reduction of oxygen concentrations from 21 to $10 \%$ inhibited the catalyzed oxidation of glucose by GOX at four different levels: (i) at the level of gene expression; (ii) GOX activity; (iii) gluconic acid accumulation in culture; and (iv) gluconic acid accumulation in apples. Reduction of environmental $\mathrm{O}_{2}$ level from 21 to $10 \%$, however, did not affect $P$. expansum growth but inhibited colonization of the host. This suggests that the limitation of fungal colonization is not a result of restriction of respiration and growth, but is probably caused by the down-regulation of gox 2 and the reduction in gluconic acid accumulation at the leading edge. It is possible that the inhibition of fungal colonization by only $15 \%$ when gluconic acid accumulation is inhibited by $63 \%$ is the result of compensation by the pathogen inducing the synthesis of other organic acids such as citric acid. Nevertheless, since reduction in GOX activity in vitro by reduced $\mathrm{O}_{2}$ concentration levels was not accompanied by a decrease in the culture pH (Fig. 4 ), it is probable that citric acid or other organic acid is not accumulated. In $B$. cinerea, down-regulation of GOX by gene knockout resulted in mutants that displayed similar virulence to that of the wild-type strain (21). In this case, it was suggested that other oxidative reactions or even alternative unidentified GOX genes provide products that contribute to fungal attack and necrosis (21).

To summarize, we have presented data that support the hypothesis that gluconic acid is a key factor contributing to fungal disease of apple. The lower exogenous $\mathrm{pH}$ likely favors the production of other fungal pathogenic factors (e.g., cell wall degrading enzymes) that contribute to tissue necrosis (18). Reactive oxygen species (ROS) detected in the infected plant tissues that are likely produced from the oxidation of glucose by GOX may also contribute to the weakening of apple tissue and securitization, in a manner similar to plant infection by Botrytis cinerea (21). Since $P$. expansum penetrates the host only through wounds, it is possible that the ROS at the host's wound are critical for initial gox activation and the initiation of Penicillium attack. In this relation, Castoria et al. (4) reported that ROS generation was detected during the first $4 \mathrm{~h}$ immediately after apple fruit is wounded. Superoxide and subsequently generated ROS may act as second messengers that control the activity of the factors(s) that regulate the transcription of hypoxic genes such as gox $(3,7)$. The fact that ROS generation in wounded tissue is more rapid and more pronounced in apple fruits stored for long period of time is consistent with the general occurrence of enhanced levels of oxidant species in senescent tissues $(4,13)$ and the susceptibility of fruits to fungal attack via their senescent tissue during storage.

\section{ACKNOWLEDGMENTS}

We thank E. Battat for his assistance. This study was supported by a grant from Israel Science Foundation (ISF) to D. Prusky and O. Pines. We thank Z. Aharon for his assistance on the gas regulation system development.

\section{LITERATURE CITED}

1. Anastassiadis, S., Aivasidis, A., and Wandrey, C. 2003. Con tinuous gluconic acid production by isolated yeast-like mould strains of Aureobasidium pullulans. Appl. Microbiol. Biotechnol. 61:110-117.

2. Bailey-Serres, J., and Chang, R. 2005. Sensing and signaling in response to oxygen deprivation in plants and other organisms. Ann. Bot. 96:507518.

3. Bunn, H. F., and Poyton, R. O. 1996. Oxygen sensing and molecular adaptation to hypoxia. Physiolog. Rev. 76:839-885.

4. Castoria, R., Caputo, L., De Curtis, F., and De Cicco, V. 2003. Resistance of postharvest biocontrol yeast to oxidative stress: A possible new mechanism of action. Phytopathology 93:564-572.

5. Dutton, M. V., and Evans, C. S. 1996. Oxalate production by fungi: Its role in pathogenicity and ecology in the soil environment. Can. J. Microbiol. 42:881-895.

6. Eshel, D., Miyara, I., Ailing, T., Dinoor, A., and Prusky, D. 2002. pH regulates endoglucanase expression and virulence of Alternaria alternate in persimmon fruit. Mol. Plant Microbe. Interact. 15:774-779.

7. Fiedurek, J., and Gromada, A. 2000. Production of catalase and glucose oxidase by Aspergillus niger using unconventional oxygenation of culture. J. Appl. Microbiol. 89:85-89.

8. Frederick, K. R., Tung, J., Emerick, R. S., Masiarz, F. R., Chamberlain, S. H., Vasavada, A., Rosenberg, S., Chakraborty, S., Schopter, L. M., and Massey, V. 1990. Glucose-oxidase from Aspergillus niger - cloning, gene sequence, secretion from Saccharomyces cerevisiae and kinetic-analysis of a yeast-derived enzyme. J. Biol. Chem. 265:3793-3802.

9. Hatzinikolaou, D. G., Hansen, O. C., Macris, B. J., Tingey, A., Kekos, D., Goodenough, P., and Stougaard, P. 1996. A new glucose oxidase from Aspergillus niger: Characterization and regulation studies of enzyme and gene. Appl. Microbiol. Biotechnol. 46:371-381.

10. Kalisz, H. M., Hendle, J., and Schmid, R. D. 1997. Structural and biochemical properties of glycosylated and deglycosylated glucose oxidase from Penicillium amagasakiense. Appl. Microbiol. Biotechnol. 47:502-507.

11. Kwast, K. E., Burke, P. V., and Poyton, R. O. 1998. Oxygen sensing and the transcriptional regulation of oxygen-responsive genes in yeast. J. Exp. Biol. 201:1177-1195.

12. Liu, S., Oeljeklaus, S., Gerhardt, B., and Tudzynski, B. 1998. Purification and characterization of glucose oxidase of Botrytis cinerea. Physiol. Mol. Plant Pathol. 53:123-132.

13. Lurie, S., and Klein, J. D. 1990. Heat treatment of apples: Differ -ential effects on physiology and biochemistry. Physiol. Plantarum 78:181-186

14. Magro, P., Marciano, P., and Di Lenna, P. 1984. Oxalic acid production and its role in pathogenesis of Sclerotinia sclerotiorum. FEMS Microbiol. Lett. 24:9-12.

15. Martell, E. A., and Calvin, M. 1952. Pages 516 and 541 in: Chemistry of Metal Chelate Compounds. Prentice-Hall, Inc., New York.

16. Murray, F. R., Llewellyn, D. J., Peacock, W. J., and Dennis, E. S. 1997. Isolation of the glucose oxidase gene from Talaromyces flavus and characterisation of its role in the biocontrol of Verticillium dahliae. Curr. Genet. 32:367-375.

17. Prusky, D., McEvoy, J. L., Leverentz, B. and Conway, W. S. 2001. Local modulation of host $\mathrm{pH}$ by Colletotrichum species as a mechanism to increase virulence. Mol. Plant Microbe. Interact. 14:1105-1113.

18. Prusky, D., McEvoy, J. L., Saftner, R., Conway, W. S., and Jones, R.. 2004. Relationship between host acidification and virulence of Penicillium spp. on apple and citrus fruit. Phytopathology 94:44-51.

19. Prusky, D., and Yakoby, N. 2003. Pathogenic fungi: Leading or led by ambient pH? Mol. Plant Pathol. 4:509-516.

20. Rando, D., Kohring, G. W., and Giffhorn, F. 1997. Production, purification, and characterization of glucose oxidase from a newly isolated strain of Penicillium pinophilum. Appl. Microbiol. Biotechnol. 48:34-40.

21. Rolke, Y., Liu , S. J., Quidde, T., Williamson, B., Schouten, A., Weltring, V. Siewers,. Tenberge, K. B, Tudzynski, B., and Tudzynski, P. 2004. Functional analysis of $\mathrm{H}_{2} \mathrm{O}_{2}$-generating systems in Botrytis cinerea: The major $\mathrm{Cu}-\mathrm{Zn}$-superoxide dismutase (BCSOD1) contributes to virulence on French bean, whereas a glucose oxidase (BCGOD1) is dispensable. Mol. Plant Pathol. 5:17-27.

22. Roukas, T. 2000. Citric and gluconic acid production from fig by Aspergillus niger using solid-state fermentation. J. Ind. Microbiol. Biot. 25:298-304.

23. Sankpal, N. V., and Kulkarni, B. D. 2002. Optimization of fermentation conditions for gluconic acid production using Aspergillus niger immobilized on cellulose microfibrils. Process. Biochem. 37:1343-1350.

24. Semashko, T. V., Mikhailova, R. V., and Eremin, A. N. 2003. Extracellular lucose oxidase of Penicillium funiculosum 46.1. Appl. Biochem. Microbiol. 39:368-374.

25. Sillanpaa, M., Pirkanniemi, K., and Dhondup, P. 2003. The acute toxicity of gluconic acid, beta-alaninediacetic acid, diethylenetriaminepentakismethylenephosphonic acid, and nitrilotriacetic acid determined by Daphnia magna, Raphidocelis subcapitata, and Photobacterium phosphoreum. Arch. Environ. Cont. Tox. 44:332-335.

26. Thordal-Christensen H., Zhang, Z., Wei, Y., and Collinge, D. B. 1997. Subcellular localization of $\mathrm{H}_{2} \mathrm{O}_{2}$ in plants. $\mathrm{H}_{2} \mathrm{O}_{2}$ accumulation in papillae and hypersensitive response during the barley-powdery mildew interaction. Plant J. 11:1187-1194.

27. Verhoeff, K., Leeman, M., Vanpeer, R., Posthuma, L., Schot, N., and Vaneijk, G. W. 1988. Changes in $\mathrm{pH}$ and the production of organic acids during colonization of tomato petioles by Botrytis cinerea. J. Phytopathol. 122:327-336.

28. Witteveen, C. F. B., Vandevondervoort, P. J. I., Vandenbroeck, H. C., Vanengelenburg, F. A. C., Degraaff, L. H., Hillebrand, M., Schaap, P. J., and Visser, J. 1993. Induction of glucose-oxidase, catalase, and lactonase in Aspergillus niger. Curr. Genet. 24:408-416.

29. Yao, C. L., Conway, W. S., and Sams, C. E. 1996. Purification and characterization of a polygalacturonase produced by Penicillium expansum in apple fruit. Phytopathology 86:1160-1166. 